\title{
El tabú de la sobrepoblación y la ética ambiental
}

\author{
Lizbeth Sagols
}

I

ntroducción: algunos datos y planteamiento ético

La sobrepoblación actual resulta excesiva, a pesar de dos hechos que parecen contradecirla. Por un lado, es cierto que algunos países como Italia, Alemania y España registran una implosión demográfica. ${ }^{1}$ Por el otro, el Census Bureau indica que el crecimiento poblacional ha sufrido un decremento del $2.1 \%$ en 1970 al $1.2 \%$ en $2003 .^{2}$ Ambos datos dan lugar, en ocasiones, a pensar que la sobrepoblación no es un tema urgente. Sin embargo, es necesario advertir que el problema población es mundial y no regional, que unos países tengan implosión demográfica no elimina la gravedad del asunto. Asimismo, el hecho de que hubo un descenso en el crecimiento de la población no indica para nada que no seamos ya demasiados, aun cuando no nos reproduzcamos con tanta efusividad como en décadas pasadas. De todas formas el incremento poblacional anterior fue excesivo. Basta con advertir que mientras en 1850 éramos 1000 millones de humanos, hoy somos más de 7000 millones). En tan sólo 160 años nos hemos septuplicado. Otro dato que ayuda a comprender lo que esto significa es que si sumamos la cantidad total de humanos desde la aparición del homo sapiens en la Tierra hasta nuestros días, tenemos un número de personas igual a la que actualmente, en un mismo tiempo, conforma la población mundial. Si ello fuera poco, la ONU nos informa también que

${ }^{1}$ Vid. D. Callahan, "Ethics and Population", en Hastings Center Report, vol. 39, núm. 3, junio, 2009. El problema, por desgracia, no es de países aislados -como piensa Callahan-, sino del mundo en su conjunto. Por otra parte, en este artículo se sostiene que el problema es ecológico, es decir, que tiene que verse en relación con los recursos básicos del planeta y no sólo en relación con la libertad reproductiva y el éxito para evitar la mortandad infantil -como también piensa Callahan, cuya visión es exclusivamente bioético-médica e ignora la relación humano-naturaleza.

${ }^{2}$ Informe Census Bureau, 2003. 
hoy en día, cada dos segundos nacen 27 niños en todo el mundo, y si sumamos los segundos en un año llegamos a una cifra semejante a la del total de nacimientos registrados por el Census Bureau de Estados Unidos: ${ }^{3} ¡ 100$ millones de nuevos habitantes en tan sólo un año!

Pero el exceso de la población actual no proviene de la mera cantidad, ni de la densidad poblacional o la concentración de la población en determinados espacios. Lo decisivo es la relación entre la densidad y el agotamiento de los recursos no renovables y de aquellos que aunque en principio son renovables, su uso excesivo los está llevando a la extinción en muchas zonas del plane$t a$ : agua, aire puro, bosques, tierra fértil, la diversidad de especies animales y vegetales y el equilibrio (relativo) de los ecosistemas. Asimismo, el exceso de seres humanos y el estilo de vida consumista está alterando de forma abrupta ciertas condiciones indispensables para todas las formas de vida como: la estabilidad del clima y el aumento de la salinidad de los mares. Lo grave es que el crecimiento poblacional exagerado está destruyendo el capital natural con el que nosotros, y otras especies, contamos para vivir.

Nuestra relación con la vida está siendo destructiva, basta con pensar que ahora se está dando la mayor extinción de especies desde que desaparecieron los dinosaurios hace 65 millones de años. Estamos perdiendo especies a un ritmo de casi 30000 por año - aunque nadie lo sabe con exactitud. La diferencia entre esta extinción y las anteriores es que en lugar de responder a un proceso planetario o galáctico, responde a los abusos antropocéntricos. Todos los humanos tenemos una gran responsabilidad ética en esto, no es válido permanecer indiferentes ni pensar que no podemos hacer nada. Hoy más que nunca, después de las múltiples críticas al antropocentrismo y la razón instrumental, ${ }^{4}$ sabemos -a pesar de los múltiples empeños por disfrazar el asunto de algunos políticos y teóricos- que somos los causantes del deterioro planetario. ${ }^{5}$ Si no fuéramos tantísimos y si no lleváramos el estilo de vida consumista que llevamos, no explotaríamos de forma excesiva a la Tierra y ella estaría en mucho mejor estado.

Por otro lado, la sobrepoblación trae consigo una creciente degradación de la vida humana. Los signos son múltiples, pero resaltan al menos tres: 1) el

${ }^{3}$ www.censubureau.com

${ }^{4}$ Vid. Hans Jonas, Principio de responsabilidad. Madrid, Herder, 1995; Eduardo Nicol, El porvenir de la filosofía. México, FCE, 1977 y Max Horkheimer, Crítica de la razón instrumental. Madrid, Trotta, 2002.

${ }^{5}$ Llama la atención, por ejemplo, la cantidad de publicaciones francesas para negar la participación humana en la crisis ecológica, algunos títulos son los siguientes: Philippe Cécile, C'est trop tarde pour la terre? Ideées Fauses, vrais réponses, 2007; André Legendre, L'homme est-il responsable du rechauffement climatique, 2009; Christian Gerondeau, $\mathrm{CO}_{2}$ : un mythe planétaire. Prefacio de Valéry Giscard d'Estaing, 2009. 
aumento del hambre y la sed en los países subdesarrollados a causa de la falta de comida nutritiva ${ }^{6}$ y agua potable (no la falta de simple comida y agua); 2 ) la imposición de la uniformidad vital: la dificultad creciente de desarrollar una auténtica individualidad con la dedicación a una forma de vida, una vocación, ${ }^{7}$ o bien conquistar una personalidad que vaya más allá de los parámetros que la sociedad impone ${ }^{8}$ e incluso alcanzar un nivel material de vida que permita el florecimiento, ${ }^{9}$ y 3) la reducción de nuestras libertades y derechos. Cada vez tenemos menos derecho a: tener un trabajo, viajar de forma libre, ser oportunamente atendido en una emergencia sanitaria, elegir el lugar de residencia, un medio ambiente sano, disponer de agua potable. ${ }^{10}$ Desde luego, la deshumanización también apela a nuestra responsabilidad ética frente a la sobrepoblación. Como lo ha precisado Derek Parfit, la cantidad de humanos afecta de forma muy seria la cualidad de nuestras vidas. ${ }^{11}$ Algo debemos hacer en vez de permanecer como espectadores de la tormenta.

\section{Los prejuicios detrás del tabú}

Sin embargo, hay resistencia a tomar en serio los datos de la población mundial y los alarmantes conflictos que implica. La crítica a la sobrepoblación está plagada de prejuicios: se piensa que estamos yendo contra la existencia humana o que pretendemos -como Malthus-dejar que los pobres, cuya existencia estaría de sobra, mueran de hambre. Entonces, la solución parece residir tan sólo en una mejor distribución de la riqueza, como si la Tierra tuviera recursos infinitos y la población pudiera crecer de forma infinita. También se piensa que hay detrás de la crítica al crecimiento poblacional una mentalidad tiránica, de medidas draconianas, como la de los políticos chinos que castigan los

${ }^{6}$ Según datos recientes de la ONU más de 1020 millones de personas en el mundo sufre de desnutrición. Vid. www.fao.org.

${ }^{7}$ E. Nicol, op. cit.

${ }^{8} \mathrm{M}$. Horkheimer, op. cit.

${ }^{9}$ Derek Parfit, "Overpopulation and Quality of Life", en Jesper Ryberg y Torbjorn Tannsjo, eds., The Repugnant Conclution. Essays on Population Ethics. Dordrecht, Kluwer Academic Publishers, 2004.

${ }^{10}$ Sandy Irvine y Alec Ponton, "Explosión demográfica", en Andrew Dobson, coord., Pensamiento verde. Una antología. Madrid, Trotta, 1999.

${ }^{11}$ D. Parfit, "Overpopulation and Quality of Life", en op. cit. Un antecedente eminente de esta idea se encuentra en La política de Aristóteles, en la cual se afirma que para que las leyes se cumplan y para que los gobernantes sean elegidos con conciencia y llevemos una vida justa, la población tiene que ser limitada. El aumento en la cantidad trae desorden y provoca la elección injusta de los gobernantes. Libro viI, cap. 4, 1326a y $1326 b$. 
nacimientos no previstos. Se piensa, así, que es mejor no limitar la libertad reproductiva. Y existe, en fin, la idea patriarcal de que el varón dejará de ser tal si no ejerce su dominio sobre la mujer teniendo el número de hijos que él quiera. Desde este punto de vista, la liberación de la mujer y la conquista de su igualdad efectiva con el varón contradice el "orden" del mundo.

Como consecuencia de estos prejuicios, la crítica a la sobrepoblación se ha convertido en un tema tabú incluso entre especialistas ambientales. Llama la atención que políticos y escritores -como Al Gore, en su famoso video "Una verdad incómoda" - se contentan con consignar las cifras poblacionales y no se atrevan a ofrecer una solución. Sólo proponen disminuir las emisiones de $\mathrm{CO}_{2}$ sin asumir que si fuéramos menos no contaminaríamos tanto, con $\mathrm{CO}_{2}$ o con cualquier otro combustible sustituto. Y es alarmante que en la reunión de Copenhague, a pesar de que el Fondo de Población de la ONU había elaborado un informe demostrando que todo ser humano implica una fuerte huella de carbono que afecta al calentamiento global y que, por ende, es urgente reducir la sobrepoblación, no se haya hablado para nada de este tema en dicha reunión. ${ }^{12}$ ¿Por qué?

La persistencia de los prejuicios contra la sobrepoblación no es casual ni mucho menos neutra, responde -como lo han advertido diversos teóricos- a los intereses de las Iglesias patriarcales (en particular la católica y la musulmana) así como de los grandes monopolios económicos. Ambas instancias se sostienen por las enormes cantidades de gente. Para los monopolios es esencial que existan masas consumidoras de la sobreproducción industrial y mercantil. Para las Iglesias, es indispensable la miseria, el sufrimiento de los fieles y, en tanto son patriarcales, se apoyan en el sometimiento de la mujer a través de múltiples embarazos y la condena del aborto. ${ }^{13}$ De hecho, el papa Wojtila pactó en 1994, en la reunión de El Cairo, con ciertos grupos para silenciar el tema poblacional y desde entonces este tema ha desaparecido de la agenda oficial de la ONU y del discurso de políticos y analistas sociales. Ahora tiene que hablarse de salud y libertad reproductiva. ${ }^{14} \mathrm{Y}$ una razón muy similar impidió que se hablara de sobrepoblación en Copenhague: en las reuniones previas, la agencia de ayuda económica a la ONU (de corte católico) la CAFOD

${ }^{12}$ www.timesonline.com, noviembre 19 de 2009.

${ }^{13}$ Paul R. Ehrlich, The Population Bomb. Nueva York, Ballantine Books, 1968; Jorge Silva, "El largo peregrinar hacia la humanización", en Revista de la Universidad La Salle. México, 2010. En prensa,

${ }^{14}$ Vid. Giovanni Sartori y Gianni Mazzoleni, La Tierra explota. Superpoblación y desarrollo. Madrid, Taurus, 2003. Frente a la denuncia valiente de estos autores, llama en extremo la atención que Callahan exalte, en el artículo citado, el cambio de discurso de la ONU como un adelanto. ¿Podemos considerarlo así? 
dijo a la ONU que retiraría su ayuda si ésta continuaba con la promoción del control de la natalidad en los países pobres. ${ }^{15}$

\section{La ética ambiental frente a la sobrepoblación}

Lo peor es que en los autores clásicos de la ética ambiental también predomina el silencio acerca de la sobrepoblación. Si alguna perspectiva está autorizada para promover la reducción poblacional es aquella que defiende la conservación del ambiente y ha criticado duramente el antropocentrismo. Pero son pocos los filósofos ambientalistas que se ocupan del tema y quienes lo hacen, lejos de criticar los prejuicios nombrados, los confirman o simplemente los asimilan de forma acrítica, sin llegar a ofrecer una salida convincente. Holmes Rolston III, desde el ecocentrismo holista, niega al final la diferencia del ser humano frente a otras especies, da primacía al conjunto de la naturaleza y ofrece una solución malthusiana. Por el contrario, Robin Attfield hace valer la humanidad sobre la naturaleza desde una defensa de la neutralidad del crecimiento poblacional que raya, a pesar de que él mismo es un biocentrista, en un antropocentrismo subyacente. Bryan Norton, por su parte, busca un equilibrio entre el ser humano y la naturaleza, pero en el terreno de un esquema racional y no en el de los hechos. Aunque considera importante limitar la sobrepoblación, la ve como un problema a futuro y evade decir cómo limitarla. Sobre todo, ninguno de estos filósofos asume la urgencia de actuar con responsabilidad ante la sobrepoblación, es decir, no la ven en verdad como un conflicto ético. Es preciso, pues, develar los presupuestos de esta manera de proceder para ir más allá en la perspectiva ética que permita hacer frente a la sobrepoblación. ¿Qué ocurre al interior de esta disciplina que no ha asumido aún la dimensión ética del conflicto poblacional? ¿Qué podemos plantear en cambio?

Rolston III en su artículo "Feeding People versus Saving Nature? ${ }^{16}$ afirma que el ser humano tiene un valor específico dentro de la evolución de la naturaleza, dado que es el ser más evolucionado desde el punto de vista genético, sin embargo, por encima de él está la naturaleza en su conjunto y ésta debe

15 www.timesonline.com, 19 de noviembre de 2009. Aparentemente, la razón por la cual se negó tal apoyo es porque en esos países la solución está en la educación de la mujer y la igualdad entre ésta y el varón, y entonces el control de la natalidad no podría darse hasta que esto se solucionara. Pero el Fondo de Población de la onu jamás propuso en su informe un control autoritario de la población, por tanto, la actitud de la Iglesia no corresponde más que a su propio afán de controlar e imponer su agenda a la ONU, como lo hizo desde 1994 en El Cairo.

${ }^{16}$ Vid. Andrew Light y Holmes Rolston III, eds., Environmental Ethics: An anthology. Malden, Blackwell, 1999, pp. 451-462. 
mantener en equilibrio a las diversas especies aun a costa de sacrificar vidas humanas. Y es que Rolston concede al conjunto de la naturaleza (incluyendo, las especies animales y vegetales integradas a la cultura y las que permanecen en estado salvaje) no sólo un valor intrínseco per se sino el máximo valor posible, es decir, todo lo demás -incluyendo al ser humano que también tiene valor per se- queda subordinado al conjunto de la naturaleza. Bajo esta idea básica, Rolston considera que tener hijos es bueno en sí mismo, pero cuando en una familia nace el décimo, se convierte en una desgracia. Así, aunque la existencia humana tiene un valor propio, en tanto ha crecido de forma desmesurada, constituye un auténtico cáncer para el planeta, pues ocasiona que para sobrevivir, los humanos agoten al máximo los recursos naturales no renovables, vitales para subsistir, y provoquen la extinción de muchas otras especies. Por ejemplo, el exceso de población humana en Zimbabwe provoca que se mate a los rinocerontes para vivir del comercio de sus cuernos. Según Rolston, si en verdad queremos salvar al planeta y reconocemos el valor intrínseco de las otras especies, no nos queda sino dejar de alimentar a los nuevos niños de Zimbabwe para que vivan los rinocerontes. Después de todo, sostiene él, si observamos los valores que influyen en nuestra forma de vida, veremos que alimentar a la gente no es una prioridad; si lo fuera, dejaríamos de hacer conciertos y grandes celebraciones para destinar ese dinero a alimentar a los pobres. Rolston no tiene entonces reparos en plantear que desde ahora, conviene resolver los males de la sobrepoblación dejando morir de hambre a algunos humanos para que el planeta sobreviva.

De esta forma, Rolston le da la razón a quienes piensan que detrás de la crítica a la sobrepoblación hay siempre una visión malthusiana. Y resulta obvio que con ello no accedemos a una solución ética del crecimiento poblacional. Como lo han destacado ya diversos críticos de la ética ambiental, el ecocentrismo, lejos de favorecer una visión ética y humanista, la pone en cuestión.

Desde luego, tenemos que buscar la forma de que los rinocerontes y tantas otras especies no se extingan, pero no puede aceptarse sin más la muerte de otros humanos pues, justo porque poseemos razón nos anticipamos a la muerte, mientras que el animal no. Asimismo, el respeto a la vida del otro es capital para la ética, decretar que algunos deben morir, aun por conservar el ambiente, es salirse del universo ético.

Por otra parte, con frecuencia se ha señalado como un problema más del ecocentrismo su concesión de valor intrínseco a la naturaleza y su ceguera ante los intereses prácticos de la subjetividad en todo lo que se refiere a la valoración del mundo natural. ¿Pero falla en verdad Rolston por hablar del valor intrínseco de la naturaleza? A mi juicio, el biocentrismo no falla precisamente por esto. Es cierto que esta postura no toma en cuenta la participación de la subjetividad en la valoración, pero ello no se debe a que le conceda valor per se 
a la naturaleza, sino a que hace de este tipo de valor un absoluto que devalúa al ser humano.

Es preciso reconocer que justo porque el valor vale siempre para el sujeto, tiene al menos dos dimensiones, ya que el sujeto las posee también. Éste tiene, en efecto, una dimensión práctica e incluso pragmática en la que entran tanto la mera utilidad (que es lo que rechaza Rolston) como la actividad y los intereses político-sociales. Pero además, la subjetividad tiene una dimensión contemplativa que le permite reconocer el valor intrínseco de algo, no como independiente de sí misma, dado que ella es quien contempla, pero sí alejada de los intereses político-sociales y los utilitarios. En esta dimensión, se reconoce que algo vale per se, por el solo hecho de existir, por ello valoramos la presencia de todo lo que existe y admiramos el mundo natural desde el punto de vista estético, espiritual o religioso. Esto resulta innegable en una relación sensible hacia la naturaleza, en la cual sabemos de forma más o menos consciente que hay algo no ético en destruir la vida.

Desde esta perspectiva, el escollo del ecocentrismo está en los dos asuntos siguientes: 1) considera que la valoración per se de la naturaleza es la única y no acepta que también están la dimensión práctica y utilitaria. Dicho en otros términos, la naturaleza y la diversidad de especies valen per se, pero hemos de reconocer que esto no significa que no las podemos utilizar, ni mucho menos que si queremos evitar su utilización excesiva tengamos que devaluar al ser humano, en cuanto a su propia condición y sus necesidades práctico-utilitarias, y debamos preferir la muerte de seres humanos a la de los rinocerontes; 2) el ecocentrismo olvida la perspectiva humana, parece no importarle la carga ética que llevaría la muerte de los niños de Zimbabwe y además, ignora por completo la liberación de la mujer mediante la limitación de la sobrepoblación; carece por completo de la perspectiva de esa "mitad del mundo" que constituimos las mujeres.

Desde una postura un poco distinta, Robin Attfield en su artículo: "Saving Nature, Feeding People, and Ethics" ${ }^{17}$ se opone de manera radical a la propuesta de Rolston. Attfield, en tanto se declara biocéntrico, también valora, al menos en principio, la naturaleza, la biosfera, pero no le concede un valor intrínseco en tanto conjunto. Según él, lo que vale de forma intrínseca son los seres individuales, los cuales tienen potencialmente la capacidad de florecer y ser autónomos. Pero siendo objetivos - nos dice Attfield- hemos de admitir que el ser humano es quien tiene un florecimiento y una autonomía mayores.

Este filósofo no se presenta como antropocéntrico, llama a su postura "objetivismo del valor" y consiste en reconocer lo que vale per se, es decir, todas las formas de vida, con lo cual confirma su biocentrismo, pero además

${ }^{17}$ Ibid., pp. 463-471. 
Attfield, en relación con los valores, da prioridad a la vida civil en tanto elabora las normas que nos rigen y la única que puede regularse a sí misma. Además, según él, en tanto cualquier individuo es lo que vale de forma intrínseca y el humano florece y vale más, cualquier nacimiento humano es valioso en sí mismo, es una bendición, aun cuando se trate del décimo hijo de una familia. Attfield considera hiriente la idea rolstoniana de la sobrepoblación como un cáncer, ante todo porque en el cáncer el crecimiento no tiene valor intrínseco, mientras que el aumento poblacional conlleva el nacimiento de seres que tienen desde antes de nacer y en potencia un valor propio. Asimismo, dicha metáfora propicia, según él, un desprecio por la humanidad que nos llevaría a pensar que algunos están de sobra. ${ }^{18}$ Por ende, no conviene decir que somos demasiados, aun cuando se estén extinguiendo muchas especies, pues ni siquiera se ha comprobado -dice Attfield- que ello esté relacionado con el incremento poblacional humano.

Lo decisivo para él es regular nuestras sociedades con normas, sistemas de justicia y organizaciones económicas. Hemos de confiar en que gracias a la capacidad de florecimiento del ser humano, éste sabrá resolver los embates del crecimiento poblacional; desconfiar de él en este punto es ofenderlo. El hambre existe porque no hemos adoptado una distribución socialista de los alimentos como la que proponen Amartya Sen y David Schmidtz. En cuanto la adoptemos (y de seguro la humanidad lo hará -dice Attfield-) la población mundial dejará de ser una amenaza.

En definitiva, Attfield piensa que la sobrepoblación aún no es inconveniente. Hay que esperar a que ella se estabilice por sí misma antes de llegar a $11 \mathrm{mil}$ millones; en ese momento, asuntos como el calentamiento global sí serían graves, ahora no lo son. Limitar en la época actual la población nos llevaría a contar con menos seres potencialmente valiosos, menos seres morales -dice de forma expresa Attfield- y nos llevaría también a detener el desarrollo sustentable de la sociedad. Sólo podremos limitar el crecimiento poblacional dentro de unos cincuenta años, cuando hayamos avanzado en bienestar y civilidad y ello implica llegar a los ocho mil millones. ${ }^{19}$ En este momento, podremos implementar políticas públicas democráticas, participativas y apoyadas en una educación de las mujeres sobre la fertilidad.

${ }^{18}$ La idea de la humanidad como cáncer le parece incluso peligrosa a Attfield, pues podría llevarnos a suspender la ayuda a enfermos y desfavorecidos y dejarlos morir.

${ }^{19}$ Para apoyar esta cifra, Attfield señala que estudios de la Comisión Mundial sobre Medio Ambiente y Desarrollo nos dicen que se puede cultivar en un 150\% más las tierras y podríamos alimentar a 11000 millones, pero en su opinión esto sí deterioraría la ecología, aumentaría el calentamiento global, la salinización de la tierra cultivada y la desertificación (Robin Attfield, Environmental Ethics: An Overview for the Twentyfirst Century. Cambridge/Malden, Policy Press, 2003, p. 126). 
Al contrario de Rolston, Attfield - a pesar de ser biocentrista- enfatiza en el tema de la sobrepoblación la importancia del ser humano. Concede un lugar específico a los individuos naturales en tanto también pueden florecer, pero a fin de cuentas, el ser humano tiene mayor capacidad de florecimiento y tiene que aumentar su desarrollo económico-social sirviéndose de la naturaleza. Llama la atención que Attfield no hable, en sus reflexiones acerca de la sobrepoblación, del agotamiento de los recursos no renovables, ni mucho menos de aquellos elementos básicos y condiciones que resultan vitales para sobrevivir. En el conjunto de su filosofía encontramos que tales recursos se tienen que regular por la responsabilidad civil, ${ }^{20}$ mas no porque el crecimiento poblacional los ponga en crisis. Quizá en cinco décadas esto sea así, por ahora, debemos seguir teniendo varios hijos.

A mi juicio, todo lo anterior nos habla de un antropocentrismo subyacente en el pensamiento de Attfield que afirma la superioridad humana y su mayor derecho a poblar la Tierra frente a otras especies. Como lo han señalado algunos comentaristas, su obra puede ser leída en clave antropocéntrica. ${ }^{21}$ Algunos consideran que esto es para bien, pero desde mi punto de vista y en relación con la sobrepoblación, ello no es favorable ni coherente con su biocentrismo. ${ }^{22}$

Por otra parte, de manera similar a como Rolston absolutiza el todo de la naturaleza, porque advierte en ella un valor intrínseco, Attfield hace una extensión injustificada del valor per se de la persona humana a los estados previos a su nacimiento. Attfield, no se contenta con reconocer, como Kant, el valor intrínseco de la persona humana, en el sentido de que es digna, única e insustituible, por el contrario, hace extensivo tal valor a los nacimientos potenciales. Desde mi punto de vista, es indispensable reconocer que el valor per se de los seres humanos se da en tanto son personas nacidas, no antes. Los Derechos Humanos declaran que "toda persona nace libre y con dignidad igual", pero no declaran nada semejante para antes del nacimiento. Por ende, no puede decirse -como lo hace Attfield- que, en su potencia de ser, el ser humano sea moral, ni que por este falso supuesto cualquier nacimiento sea una bendición. Los ya nacidos podemos decir -quizá-que nacer es una bendición, igual que comer bien y tomar un medicamento adecuado, pero es innegable que comer o ingerir medicamentos en exceso conlleva grandes males. De igual forma, el exceso de nacimientos está trayendo graves conflictos al ser humano

${ }^{20}$ Vid. A. Light y H. Rolston III, eds., op. cit.

${ }^{21}$ H. F. Arribas, "El valor intrínseco de la naturaleza", en Isegoría, núm. 34, enerojunio, 2006, pp. 261-275. En este artículo Arribas precisa, además, que la ética y la práctica ambiental de Attfield está ligada a comunidades de trabajo del Perú que son de tradición judaica, cristiana e islámica (ibid., nota 12).

${ }^{22}$ Idem. 
y al planeta. Del hecho de que algo sea bueno no se desprende que su aumento sea mejor. ${ }^{23}$ Asimismo, la condición moral del ser humano depende de su práctica real, no potencial. Afirmar lo contrario es concebirnos -junto con la tradición aristotélico-tomista y católica- como una sustancia cuyas propiedades se dan de manera inalterable, desde el principio y hasta el final.

Además, no queda claro por qué si Attfield es capaz de avizorar políticas democráticas y educativas - que dicho sea de paso son las únicas con las que podemos combatir la sobrepoblación- no podamos empezar ya a combatirla y hayamos de esperar a ser 8 mil millones. Esto sólo se explica si nos autocomplacemos en ser más o si, por alguna razón -como las creencias católicastememos detener los nacimientos y somos ciegos al papel que juega aquí la mujer. No hay en Attfield ninguna mención al sometimiento de las mujeres -respecto al varón- al aceptar tener muchos hijos y algunos de ellos no deseados. Pero si en verdad nos interesa la calidad de vida del varón y la mujer, y las oportunidades para que florezcan, hemos de limitar los nacimientos desde ahora y no dentro de cuarenta o cincuenta años. No es ético dejar de actuar en el presente en función del valor intrínseco de la humanidad, por el contrario, es ético advertir que ésta se está deteriorando por la cantidad excesiva. Se da en ella una relación inversa entre cantidad y cualidad. ${ }^{24}$ En el fondo, el planteamiento de Attfield es un eco del prejuicio de que criticar el crecimiento poblacional es ir contra la humanidad y que bastaría con una distribución socialista de los recursos para arreglar nuestros males. Además, está implícito en los desarrollos de Robin Attfield el prejuicio de que las mujeres han de tener los hijos que el varón quiera y que, por ende, no resultaría conveniente liberarlas.

Una postura abiertamente antropocéntrica, pero acaso menos exaltadora de lo humano que la de Attfield, es la de Bryan Norton. En su artículo: "Enviromental Ethics and Weak Anthropocentrism" ${ }^{25}$ nos advierte que le interesa tan sólo proponer un marco teórico de trabajo, acompañado de principios, congruente con una visión racional del mundo y que, al menos por el momento, no le preocupa la verdad de su esquema. Bajo este horizonte, habla de antropocentrismo "débil" para distinguirlo del que se da en el utilitarismo hedonista: del consumo y la explotación. Según Norton, hemos de partir de los intereses humanos, puesto que somos nosotros quienes regulamos la relación con la naturaleza y es un hecho que necesitamos progresar, pero debemos actuar siempre conforme al ideal de proteger a la naturaleza y no destruir a las otras especies. Dicho ideal es una guía de la acción, no implica en modo alguno que la naturaleza tenga valor intrínseco, pues si así fuera, ella valdría

\footnotetext{
${ }^{23}$ A. Dobson, "Introducción", en op. cit., p. 12.

${ }^{24}$ D. Parfit, "Overpopulation and Quality of Life", en $o p$. cit.

${ }^{25}$ Vid. A. Light y H. Rolston III, eds., op. cit., pp. 163-174.
} 
con independencia de nuestros intereses y lo cierto es que el mundo natural nos interesa como recurso, pero también como belleza y como inspiración de ideas religiosas y espirituales. Para él no sólo resulta imposible pensar la naturaleza sin relación con nosotros, sino además sin los intereses políticos y sociales. Los valores no sólo los construye el ser humano, sino que lo hace en la política, es decir, tomando en cuenta los intereses colectivos.

De acuerdo a lo anterior, Norton piensa la naturaleza como si fuera una "fundación heredada" de la que nos hemos de hacer cargo, con un fideicomiso propio -que corresponde a los recursos no renovables- y que hemos de administrar lo mejor posible guiándonos por preferencias consideradas y no sólo sentidas, es decir, deben predominar las preferencias deliberativas que toman en cuenta los efectos a largo plazo.

La sobrepoblación, por su parte, pertenece a un conjunto de conductas que han de ser evitadas por la ética ambiental. Para ello, debe calcularse la proporción entre los habitantes y el flujo de recursos a fin de lograr un equilibrio entre el desarrollo social y la salud de la naturaleza que hemos de heredar a las nuevas generaciones. Sin embargo, Norton no precisa los criterios de tal equilibrio, porque en el fondo para él, el crecimiento poblacional -igual que para Attfield, no es un conflicto actual. Norton considera de manera expresa que si continuamos con las políticas poblacionales de la actualidad crearemos una severa sobrepoblación y afectaremos de forma muy seria al ambiente. El problema es entonces para el futuro, no para el presente. Así, Norton no ve la necesidad de poner límites a la población de hoy en día. Por un lado, refuerza esta idea con el hipotético caso de que una generación entera decidiera esterilizarse para poder consumir sin causar daño a sus hijos. Frente a ello, afirma el imperativo de la reproducción como un principio ético: no podemos dejar de reproducirnos porque un universo con conciencia es mejor que uno sin ella. De esta forma, Norton exalta, aun sin quererlo, la reproducción, evita la limitación poblacional y es ciego ante el sometimiento patriarcal de la mujer. Por otro lado, nos propone confiar en que la tecnología ofrecerá sustitutos a los recursos no renovables, como lo ha hecho con el combustible de carbono. Si podemos dejar estos sustitutos a las futuras generaciones no tenemos porque preocuparnos del gasto que hagamos. De nuevo, nos da razones para no limitar la población mundial, en vez de hacerlo.

Con Norton parecemos escapar por fin al predominio en ética ambiental de la naturaleza o del ser humano, ambos términos parecen reunirse en el modelo de la fundación que hemos de administrar. Y es que Norton concibe los valores desde una subjetividad práctica capaz de incorporar a la naturaleza como ideal; por tanto, no excluye al mundo natural: ni sujeto ni objeto adquieren un carácter predominante. Ésta es su gran ventaja. Sin embargo, la subjetividad en Norton excluye la dimensión contemplativa del sujeto. Podemos 
pensar que esto no afecta en nada a su postura ambientalista, pues de todas formas reconoce el valor de la naturaleza por su belleza e inspiración religiosa y espiritual como un ideal que coincide con una visión racional del mundo. No obstante, al moverse Norton sólo en el terreno de lo ideal (lo que coincide con el afán de ofrecernos sólo un marco teórico y razonable) sin necesidad de ver si es verdadero o falso, deja a los ideales sin referencia en algún rasgo del ser humano o de lo que llamamos realidad; los ideales quedan reducidos al puro idealismo y pierden fuerza motivadora. Y lo mismo ocurre con un marco teórico que no se ocupa de los hechos concretos; pierde eficacia. No es difícil advertir que el quedar encerrado en el ámbito conceptual es lo que impide a Norton ofrecer una salida a la sobrepoblación actual. Sólo en el terreno de una razón adecuada a sí misma y sin referencia a los hechos, puede plantearse el caso hipotético de que toda una generación decidiera esterilizarse ${ }^{26}$ y sólo en este terreno puede afirmarse, en las circunstancias presentes, que tenemos el deber ético de reproducirnos, sin señalar un límite preciso para ello.

En el fondo, el antropocentrismo "débil" de Norton en tanto no puede ocuparse de lo real, acaba siendo tan complaciente con el crecimiento poblacional como la postura de Attfield: concentra su atención en el ser humano, no quiere limitar la cantidad de nacimientos y no acaba de asumir el conflicto que representa la sobrepoblación para la naturaleza. Prueba de ello es que Norton no habla de los elementos y condiciones indispensables para sobrevivir. Nos dice que la tecnología puede crear sustitutos de combustibles fósiles; no dice ni una palabra sobre qué hacer con la escasez mundial de agua potable (que en algunos países como México está imponiendo la carestía como normalidad), con la contaminación del aire (que ha cobrado ya múltiples muertes humanas, animales y vegetales) con la falta de bosques y tierra fértil (que ocasiona el hambre) y con el cambio climático (que amenaza con hacer casi imposible la vida en la Tierra). Hasta ahora, no hay ningún sustituto tecnológico de todos estos recursos. E igual que en Attfield, no hay en Norton ni una mención sobre el significado existencial que tiene para las mujeres sostener el crecimiento poblacional.

Frente a estas posturas polarizadas considero, en síntesis, que la ética ambiental debe deshacerse del peso de los prejuicios y admitir, sin reservas, la urgencia de limitar la población mundial. Considero que en especial en el tema de la sobrepoblación, la ética ambiental o la ecoética está obligada a

${ }^{26}$ La idea de que toda una generación pudiera decidir no reproducirse carece de realidad por la simple y sencilla razón de que en las cuestiones de la vida y la muerte hay una gran variedad de opiniones y pasiones. Algunos querrán no reproducirse, y quedar sin descendencia, otros querrán adoptar, y otros sí se reproducirán. En esto no puede haber consenso. 
atender los hechos urgentes y no quedar atrapada en los esquemas conceptuales. ${ }^{27}$ Pienso, asimismo, que la ética exige que la limitación del crecimiento poblacional se haga sin dejar morir de hambre a nadie, sin métodos impositivos y tiránicos y sin ningún desprecio por la humanidad. Nadie de los ya nacidos está de sobra, pero todos hemos de contribuir con responsabilidad ética a detener la crisis ecológica y a propiciar formas más humanizadas de vida creando conciencia de que un índice de nuevos nacimientos como el actual, amenaza las otras formas de vida, a la humanidad en su conjunto y la liberación de la mujer. ${ }^{28}$ Esto implica, por supuesto, desarrollar una educación democrática -como la prevista por Attfield-sólo que para lograr la limitación de la fertilidad hemos de educar a mujeres y varones y no sólo con relación a la reproducción, sino también hemos de mostrar los inconvenientes de exaltar al ser humano o al todo de la naturaleza, pues esto trae una inevitable subordinación entre ambos: hemos de educar mostrando la relación igualitaria humanonaturaleza. ${ }^{29}$ Conviene, asimismo, educar más allá del patriarcado, en una igualdad mujer-varón y trascender con ello la más terrible opresión que ha sufrido la humanidad, la de la mujer, mitad del género humano, y que es la principal fuente cultural de la sobrepoblación. ${ }^{30}$ No es cierto que el varón pierda con esta igualdad, por el contrario, quedará dignificado y humanizado si aprende a aceptar la libertad reproductiva de la mujer.

En particular, en la situación presente hemos de reconocer que si tenemos consideración ética hacia el ser humano (varón y mujer) y la naturaleza, nos

${ }^{27}$ Derek Parfit, desde el utilitarismo y no desde la "ética ambiental" ha tenido el denuedo de abandonar el esquema conceptual del "utilitarismo agregativo" al darse cuenta de que, en los hechos, tal esquema nos lleva a una "conclusión repugnante": es preferible una sociedad de una mayor cantidad de personas aunque su calidad de vida sea peor, a la de una sociedad de menos personas con mayor calidad de vida (Vid. "Overpopulation and Quality of Life", en $o p$. cit). Así pues, son los hechos y no los esquemas los que deben predominar.

${ }^{28}$ También Paul Ehrlich asume, como Parfit, la necesidad de abandonar los esquemas y atender a los hechos urgentes. Y él sí lo hace desde una postura ecoética (Vid. "Ecoethics: Now Central to all Ethics", en Journal of Bioethical Inquiry, vol. 6, núm. 4, 2009) sólo que las soluciones que ofrece a la sobrepoblación en The Population Bomb, son antidemocráticas: poner anticonceptivos en toda la comida que se vende, y son malthusianas: suspender la ayuda a los países que no puedan sostenerse por sí mismos. Todo ello no va de acuerdo con la ética. No obstante, Ehrlich ha moderado sus soluciones en su último libro: The dominant animal.

${ }^{29}$ En esta relación resulta innegable reconocer cierta centralidad del ser humano, éste es el agente, el administrador, el creador de valores, pero ha de tratarse de un antropocentrismo débil, según la expresión de Norton, capaz de incorporar la naturaleza no como ideal humano, sino como una condición de nuestra existencia concreta.

${ }^{30} \mathrm{~J}$. Silva, "El largo peregrinar hacia la humanización", en op. cit. y S. Irvine y A. Ponton, op. cit. 
conviene además de educar, diseñar políticas participativas de control natal. Tales políticas no por fuerza han de ser draconianas, pueden darse a través de estímulos y, ante todo, mediante campañas públicas creadoras de conciencia. Y no cabe duda que conviene tener un mejor reparto de la riqueza y los recursos, y combatir el estilo de vida consumista en que vivimos hoy, todo ello contribuirá a aminorar en lo posible la crisis ecológica, pero mientras seamos tantos, nada se logrará. El problema es multicausal, pero la sobrepoblación es la causa principal. ${ }^{31}$

La ONU ha calculado el límite de dos hijos para no causar más daños al planeta; corresponde a todos nosotros crear conciencia pública para asumir esta responsabilidad e incluso mejorarla, por ejemplo, trascendiendo la idea egocéntrica de que los hijos han de ser de la propia sangre y buscando las mejores condiciones para que al menos uno de estos dos hijos pueda serlo por adopción. ${ }^{32}$

${ }^{31}$ G. Sartori y G. Mazzoleni, op. cit.

${ }^{32}$ D. Callahan, "Ethics and Population", en op. cit. Por otra parte, quiero dejar constancia aquí de que la actitud timorata de los éticos ambientalistas frente a la sobrepoblación contrasta con las acciones concretas de grupos de ciudadanos como Global Population Speak Out, quienes reunieron más de cien personalidades intelectuales a nivel mundial y los presionaron a comprometerse con el tema de la sobrepoblación. Además han continuado con múltiples acciones para crear conciencia acerca de este incuestionable problema. Vid. www.gpso.wordpress.com. 